\title{
Two Studies of Autonomous Sensory Meridian Response (ASMR): The Relationship between ASMR and Music- Induced Frisson
}

\author{
ALEXSANDRA KOVACEVICH[1] \\ Ohio State University \\ DAVID HURON \\ Ohio State University
}

\begin{abstract}
In recent years, a widely popular phenomenon has emerged as exemplified in thousands of videos available on the Internet. Referred to using the impressive sounding term "Autonomous Sensory Meridian Response" (abbreviated ASMR), followers claim that ASMR videos evoke a special "tingling" sensation that is regarded as highly pleasurable and relaxing. The popularity of this phenomenon is reflected in individual ASMR videos receiving more than 43 million views and a reddit ASMR forum with over 130,000 subscribers. Two exploratory studies are reported. In the first study, a content analysis was carried out on 30 popular ASMR videos, and compared with 30 videos employing two different control methods. In the second study, a content analysis was carried out on 3,600 comments on discussion forums and accompanying ASMR videos. The results indicate that ASMR videos typically employ a quiet, private scene, with a relaxed, friendly, and intimate actor ("ASMRtist"). Although ASMR is evoked by non-musical stimuli, the physiological responses to ASMR (skin-related tingling and goosebumps) strongly resemble the classic frisson experience - a phenomenon that has received considerable attention among music perception researchers. Careful consideration of ASMR stimuli and responses suggest that ASMR is consistent with Huron's (2006) theory of frisson.
\end{abstract}

Submitted 2017 August 11; accepted 2018 September 7.

KEYWORDS: ASMR, autonomous sensory meridian response, frisson, pleasure

\section{INTRODUCTION}

IN the past several years, media reports have drawn attention to a newly popular phenomenon known as autonomous sensory meridian response (ASMR) (e.g., Cheadle, 2012; Taylor, 2013, 2014; Tufnell, 2012). The phenomenon refers to a particular feeling state or states that are evoked by specially recorded videos. Widely available on popular video services such as YouTube, the videos involve individual actors/artists (commonly called ASMRtists) who enact everyday scenarios such as cutting hair, sorting through papers, putting on makeup, etc. The recordings commonly feature an actor (usually female), speaking directly to the camera using an intimate tone of voice. Viewers are encouraged to view the videos using headphones. As we will see, people often react to these videos with a feeling of confusion (and disbelief that anyone would find these videos compelling). However, dedicated followers find that the videos evoke strong feelings, commonly described as an intensely pleasurable "tingling" sensation. Indeed, ASMRtists note that they explicitly set out to create videos that evoke this response.

Apart from popular press reports, ASMR has been the subject of a handful of research studies (Barratt \& Davis, 2015; Fredborg, Clark, \& Smith, 2017; McErlean \& Banisssy, 2017; Smith, Katherine, \& Kornelsen, 2016). In their recent review of the ASMR literature, del Campo and Kehle (2016) explicitly suggest that ASMR might be regarded as a mild form of frisson. Both music-induced frisson and ASMR are pleasurable experiences associated with pilomotor responses (goosebumps). In this paper, we offer new empirical evidence consistent with this idea. We report on two exploratory studies of ASMR. The first 
study focuses on the nature of ASMR-inducing stimuli, while the second study focuses on descriptions of ASMR responses. After treating ASMR on its own terms, we then offer an interpretation of the phenomenon highlighting similarities and differences to music-induced frisson. The results are shown to be consistent with Huron's (2006) theory of frisson.

\section{ASMR}

Although the phenomenon of autonomous sensory meridian response has only recently gained substantial online prominence, the response is reportedly not new. Many proponents of ASMR report that they first experienced the response as a child (Barratt \& Davis, 2015). For many, the Internet and social media facilitated awareness of other people who have similar experiences (Cheadle, 2012). Online communities began forming around the idea of an "Attention Induced Head Orgasm" in the late 2000s, notably with the development of the Yahoo group, the "Society of Sensationalists," in 2008 (Taylor, 2014). The current popular designation, Autonomous Sensory Meridian Response, was eventually coined by Jenn Allen, the founder of an ASMR website (Cheadle, 2012).

In media accounts, the sensation is frequently likened to "brain orgasms." Relatively little empirical work has been conducted on this subject. Three studies have surveyed viewers about their experiences (Barratt \& Davis, 2015; Fredborg, Clark, \& Smith, 2017; McErlean \& Banisssy, 2017). Barratt and Davis's exploratory survey recruited self-identified ASMR aficianados from the ASMR subreddit, and surveyed viewer demographics, viewing habits, triggers, location of ASMR, and purposes for viewing ASMR. They additionally looked into potential relationships between ASMR and synesthesia, misophonia, flow-state, and mood. They found that most people prefer to watch ASMR before bed, in quiet and relaxed environments, with binaural headphones. The identified whispering, attention, crisp sounds, and slow movements as the most common triggers. Most viewers experience ASMR in a consistent position, often as a tingling sensation originating at the back of the scalp, progressing down the spine and to the shoulders. Most viewers listen to ASMR for relaxation, to help sleep, and to deal with stress. Fredborg et al. also recruited ASMR viewers via reddit, and surveyed viewers regarding five major personality domains and their ASMR experiences. Their results indicated that ASMR users score significantly higher on neuroticism and openness to experience, but lower on conscientiousness, extraversion, and agreeableness. In addition, they identified five factors that could independently predict viewers' perceived intensity ratings: watching, touching, repetitive sounds, simulations, and mouth sounds. McErlean and Banissy similarly investigated personality traits associated with experiencing ASMR. They also surveyed viewers regarding the Big Five personality inventory, and additionally about the Inter-personal Reactivity Index, as well as viewer preferences and motivation. Like Fredborg et al., their results indicated that ASMR viewers scored higher regarding openness to experience and lower on conscientiousness, but found no differences with regard to neuroticism, agreeableness, or extraversion. The Inter-personal Reactivity Index indicated that ASMR viewers scored higher with regards to fantasizing and empathic concern. McErlean and Banissy's survey results aligned with and expanded upon Barratt and Davis's survey results, regarding viewer preferences and motivations. They concluded that viewers predominantly watch ASMR videos to relax, fall asleep, and ease anxiety, and further expanded Barratt and Davis's list of popular triggers.

Two additional studies have attempted to glean further understanding of ASMR via functional imaging techniques: an fMRI study examining the default mode network (DMN) of individuals who experience ASMR, and an unpublished fMRI study carried out by an undergraduate student (Lochte, 2013; Smith et al., 2016). Smith et al. found that the default mode network in ASMR-experiencing individuals showed significantly less connectivity than controls. They suggest that this may be a blending of multiple resting-state networks, and such undifferentiated networks can be associated with atypical conscious experiences and perceptions.

ASMR bears some similarity to the phenomenon of frisson (pleasant chills or shivers), frequently induced by music, film, video games, and amusement-park rides. In the case of music, a number of studies have examined the behavioral, physiological and musical concomitants (Blood \& Zatorre, 2001; Colver \& El-Alayli, 2016; Craig, 2005; Gabrielsson \& Lindström, 1993; Gabrielsson \& Lindström, 2003; Goldstein, 1980; Grewe, Nagel, Kopiez, \& Altenmüller, 2007; Guhn, Hamm, \& Zentner, 2007; Halpern, Blake, \& Hillenbrand, 1986; Huron \& Margulis, 2010; Konečni, 2015; Konečni, Wanic, \& Brown, 2007; Maruskin, Thrash, \& Elliot, 2012; Panksepp, 1995; Panksepp \& Bernatzky, 2002; Rickard, 2004; Sloboda, 1991). However, aficionados of ASMR claim that ASMR differs from the experience of frisson (Collins, 2012; Higham, 2014). 
In any seemingly new phenomenon, it is appropriate to begin empirical research by focusing on exploratory studies. Accordingly, we carried out two studies. The aim of the first study is to describe the content of the ASMR videos, whereas the aim of the second study is to describe written commentaries reporting the responses of viewers.

\section{STUDY 1}

On YouTube, a search for "ASMR" produces over 8,700,000 hits of nominally distinct videos in which the term ASMR is present in the video title. Similarly, a Google "video" search for "ASMR" produces over 5 million hits (accessed July 23, 2017). The phenomenon is not obscure. On YouTube, the top 10 ASMR videos report between 9 million and 43 million views (accessed July 23, 2017).

The videos typically range between 10 and 50 minutes in length and feature a variety of activities, from a faux haircut to leafing through a stamp collection. In order to better characterize the content of these videos, we carried out a formal sampling procedure, including sampling of control videos. We then followed an a priori method for analyzing the content of both the ASMR and control videos.

\section{Sample}

For the purposes of this study, we selected the 30 most popular ASMR videos. These were selected by searching for the term "ASMR" on YouTube and selecting the 30 videos with the highest number of views. All searching was done using private browsing in order to minimize the selection effects arising from browser history and marketing profiles. Within the world of ASMR, there are several popular ASMR producers. This includes individual ASMRtists such as GentleWhispering and Heather Feather. In order to increase the independence of the sampled items, we a priori included no more than three videos by a single artist.

Most ASMR videos are in English; however, large active discussion forums can be found in other languages, notably Japanese and Korean. Moreover, some of the English-language videos have been produced by non-native English speakers. For the purposes of this study, we limited our sampled material to English. Using our popularity criterion, our sample included three videos by non-native (Russianaccented) speakers. Most of the remaining videos employed American-accented speakers, with two videos involving a British-accented speaker, and two involving an Australian-accented speaker.

Some ASMR-related videos are explanatory in nature rather than intended to evoke the experience. These videos typically feature a person offering a tutorial, explanation, or guide to the purported ASMR phenomenon. These videos were explicitly excluded from our sample. In addition, we excluded ASMR parodies, and any "videos" that consisted of a still image with overlaid audio.

Using these criteria, we selected 30 videos by 18 distinct producers. Of the 30 videos, 25 featured female artists, 2 featured male artists, and 1 featured both a male and female. Two of the videos had no discernible actors. All of the materials were accessed through YouTube.

\section{Control Sample}

If our aim is to describe the unique content of ASMR videos, we must necessarily compare that content with other similar videos. It is not entirely clear what constitutes an appropriate control group. Accordingly, we selected two control conditions. One control group consists of general videos ("general control videos") posted on the same websites that include ASMR videos. In particular, since videos range wildly in terms of their popularity, it would be most appropriate to select control videos that have a similar number of views.

In locating suitable control videos, some sort of search term or search criterion is needed. We were concerned that just about any search term might introduce an unwanted bias. Even words like "neutral" can produce subtly biased results. Initially, we aimed to search for videos whose release or posting date matched the date of posting for each of the target videos. Having identified a number of videos with the same posting date, we would then select as a control video that video that best matched the number of views to the target ASMR video. However, the YouTube search interface still requires some sort of search term in order to return a list of videos. As a result, we made use of six low-content words as search terms. Specifically, we used the terms "the," "an," "with," "and" "for" and "from" as keywords for the searches. 
We used each term to select five videos, resulting in 30 control videos. Consequently, our "general control" videos, shared the same date of posting and a roughly equivalent popularity in terms of the number of views. It should be noted that our search criterion unexpectedly returned a number of music videos. Since ASMR videos rarely include music, we also discarded the music videos as unsuitable controls.

Posted videos differ dramatically in terms of their content. These may include vacation videos, pet or animal behaviors, birthday parties, sporting events, humorous antics, natural disasters, and so on. Nearly all ASMR videos involve a single person in an indoor setting addressing the camera. Accordingly, our second control sample sought to match these same gross features. Specifically, we aimed to select videos from the same websites in which a person addresses an imagined audience of viewers in an indoor setting ("talking-head control videos"). In this second control sample, no effort was made to match the videos in terms of popularity, or with regard to the date of posting. In order to identify suitable videos, we found that the search term "tutorial" led to many videos in which a single person addresses the camera and explains or describes some activity, such as how to apply makeup, commentaries on current events, etc. For this second control group, we matched the same proportion of male and female actors. Some ASMR videos include more than one actor, so these were matched with control videos involving an equivalent number of actors. In selecting "tutorial" videos as controls, we recognize that tutorial, lecture, or commentary videos might be expected to exhibit their own distinctive vocal mannerisms. Once again, videos in which music was prominent were also excluded.

\section{Content Analysis}

For the purposes of this study, we devised an a priori custom protocol for content analysis of the videos. In order to select measures for comparison, we began by referencing the online community and existing media. We reviewed news articles, forums, and blog posts to develop an idea of what viewers perceive to be crucial aspects of the stimuli. We additionally conducted an interview with a self-identified ASMR aficionado. A synopsis of this interview is available in Appendix 1. Both online sources and the interviewee suggested that attributes of the ASMRtists themselves are fundamental to the ASMR experience, so we developed several measures to describe the actor (Richard, 2014). Users further reported that topical content and setting often influence a video's effectiveness (Cheadle, 2012). As such, we included measures that capture aspects of the content and setting. The interviewee also identified several perceived auditory requirements for ASMR triggers. With this, we included measures which describe the audio. Additionally, as ASMR potentially shares similarities with frisson, we included measures which capture known triggers of frisson. Existing literature provides evidence that certain auditory elements play a vital role in triggering the frisson response in viewers (Huron \& Margulis, 2010). Frisson is often induced by acoustic correlates such as rapid and large increases in volume, broadening of the range of frequency, or entry of new instruments (Panksepp, 1995). As such, we included several measures which capture these auditory elements. Ultimately, we determined to analyze the video content with regard to four major areas: the person, the speech/audio, the topical content, and the setting. The content analysis protocol is detailed in Table 1.

All measures (except where noted) were taken from a randomly selected 60 -second excerpt. The randomization procedure was devised so that all portions of the video were equally likely to be sampled. In the case of "setting," it is common for camera angles or degree of zoom to change from time to time. Accordingly, the coding was done for only the first camera scene/angle in the randomly selected excerpt.

In analyzing "speech/audio," shorter samples were used, ranging from between 5 and 10 seconds selected from the randomly sampled 60-second excerpt. Spoken passages are sometimes obscured by prominent background sounds. In these situations, we used the first subsequent unmasked or unobscured speech segment for analysis. In some cases, the sampled excerpt lacked isolated speech. In these cases, sampling of the video continued until a speech passage was identified. In a few videos, the entire video was devoid of speech: this fact was coded separately. In the case of subjective estimates, all coding was carried out twice - once by one of the authors, and a second coding by an independent rater unfamiliar with the study or the project objectives. 
Table 1. Detailed protocol for content analysis.

Measure

Coding procedure

The Person

1. Face Time

2. Hands Time

3. Actors

4. Sex

5. Age

6. Face frame

7. Face forward

8. Eye contact

9. Makeup

10. Dress

11. Smiling

Speech and Audio

12. Mic visibility

13. Vocal energy

14. Oral wetness

15. Syllable rate

16. Word complexity

17. Loudness non-speech

18. Proportion non-speech

19. Audio roaming

20. Dorsal sound

21. Proximity

22. Sound pointing
The proportion of time in the video sample in which a person's face is visible in the frame.

The proportion of time in the video sample in which a person's hands are visible in the frame.

The maximum number of people present in the video sample.

The apparent sex of individuals appearing in the video sample, encoded as the proportion of "maleness" (0-1).

The average estimated age of all individuals appearing in the video sample.

The vertical proportion of the frame occupied by a face (when present).

Proportion of the time in which the face is directly facing the camera.

Proportion of the sampled time in which eye contact is made with the camera.

Presence of makeup (subjective rating from none "1" to heavy makeup "5").

Style of dress (subjective rating from intimate "1" to professional "5").

Proportion of the sampled time in which the person is smiling.

Whether or not the microphone is visible.

Subjective rating of vocal energy (whispering "1" to shouting "5").

Subjective impression of oral wetness (dry mouth " 1 " to wet mouth " 5 ").

Both the number of words and syllables was counted over a 15 -second sample. The syllable rate was used as a measure of speaking rate.

Compared with professional or technical conversation, casual conversation commonly exhibits more monosyllabic words. Consequently, we measured the average number of syllables per word in the sampled sequence as an index of the technical sophistication of the speech.

Loudness of non-speech sounds (quiet "1" to loud "5").

Proportion of non-speech sounds over a 60-second sample.

Subjective impression of the amount of movement for the sound sources (no movement "1" to high movement " 5 ").

Subjective impression of the occurrence of sound behind the listener (no dorsal sound " 1 " to frequent dorsal sound " 5 ").

Average estimated distance between microphone and speaker (in meters).

Drawing attention to sounds (subject impression of the amount of attentiondrawing from none " 1 " to explicit frequent attention " 5 "). 
23. Voicing

24. Pitch

25. Pitch variance

26. Music
Proportion of a random 5-10 second excerpt when the voice is sounding (proportion of pulse time measured using the PRAAT voice analysis software).

Average pitch of the voice over the same random 5-10 second excerpt. (Mean F0 as measured using PRAAT).

Average pitch excursion (or F0 variance) over the same random 5-10 second excerpt.

Subjective impression of the proportion of music (no music "1" to constant music "5").

Nature of the activity (open-ended coding).

Judgment of the intimacy of the activity (low "1" to high "5").

Count of the number of occurrences of single first-person words $I, m e, m y$, mine.

Count of the number of occurrences of plural first-person words we, us, our, ours.

Count of the number of occurrences second-person words you, your, yours when addressed to the camera (as opposed to a second actor).

Setting
An estimate of the physical distance (in meters) between the top and bottom of the picture.

Indoor versus outdoor (scale of 1 "indoor" to 5 "outdoor").

Domestic versus professional setting (scale of 1 "domestic" to 5

"professional").

Private versus public setting; e.g., bedroom versus lobby (scale of 1 "private" to 5 "public").

A subjective rating between dark " 1 " and bright " 5 ".

Quiet "1" versus noisy "5".

Open-ended description of background (e.g., color, soft versus hard surfaces, etc.).

\section{Results}

In the case of the subjective estimates, codings by our independent rater allow us to calculate the inter-rater reliability. The degree of agreement between raters was calculated using a Kappa statistic across all 13 numerical subjective measures. This included such judgment categories as lighting level, makeup, style of dress, vocal energy, oral wetness, etc. The Kappa statistic was a rather low .47, indicating only a moderate correlation across all ratings. For this first study, we only used the first rater's ratings (who was one of the authors). The second rater's data was simply used to calculate the interrater reliability

The results of our analyses are reported in Table 2. The three columns in Table 2 report the means and standard errors for the each of the three video conditions (ASMR videos, general control videos, and talking-head control videos). In addition, $p$ values are reported comparing each control condition with the ASMR condition. Given the large number of tests performed, a Bonferroni correction would require .00071 corresponding to $p=.05$, or .00014 corresponding to $p=.01$. Significant values have been marked with single $\left(^{*}\right)$ or double asterisks $(* *)$ accordingly. In order to help visualize effect sizes, relationships between the three conditions are graphically represented in Figure 1 for all measures exhibiting $p$ values below 05 . 
Compared with both the general control videos and the talking-head control videos, ASMR videos appear to exhibit significantly more oral wetness cues, audio roaming, and intimacy but less vocal energy, syllable-rate, and voicing.

ASMR videos showed additional differences in comparison to only one of the control groups. Overall, compared to the general control, ASMR videos exhibited less music, decreased frame-size, and a decreased loudness of non-speech sounds. The videos also showed a greater proportion of female actors, greater proportion of the frame occupied by the actor's face, increased proximity, and increased use of makeup. The videos also showed an increased tendency to be in a private setting as compared to a public setting. In comparison to the talking-head control group, the ASMR videos showed decreased proportion of non-speech sounds.

Our measures showed no statistically significant differences for ASMR videos with regard to the amount of face time, the amount of hands time, the number of actors, average age of actors, the level of lighting, the amount of time the actor faces forward, the amount of eye contact, the formality of attire, the amount of smiling, the amount of sound pointing, the amount of dorsal sound, word complexity, microphone visibility, pitch of voice, the variance of the pitch of the voice, the number of singular selfreferences, the number of plural self-references, the number of references to the observer, the tendency to be indoors versus outdoors, or the tendency to be in a domestic versus a professional setting.

Apart from the formally-coded observations, recall that the two raters were asked to provide openended general observations with regard to the background and the activity for all of the videos. General observations regarding background simply reflect the findings of the formally-coded results, namely that the background environment tends to be more private and indoor. With respect to the type of activity, the open-ended observations drew attention to the implicit understanding that the sounds in ASMR videos are important, whether or not the actor engaged in explicit sound "pointing." In addition, it was observed that ASMR videos typically involve some sort of role-playing in which the viewer is considered a subject in the interaction. For example, the viewer may be a patient in an eye examination, a patron in a spa, recipient of a foot massage, having a bra fitting at Victoria's Secret, or a customer who is booking a hotel room in outer space. 
Table 2. Results of Study 1 content analysis.

\begin{tabular}{|c|c|c|c|c|c|}
\hline \multirow[b]{2}{*}{ Category } & \multirow{2}{*}{$\begin{array}{c}\text { ASMR } \\
M(S E M)\end{array}$} & \multicolumn{2}{|c|}{ General control } & \multicolumn{2}{|c|}{ Talking-head control } \\
\hline & & $M(S E M)$ & $p$ & $M(S E M)$ & $p$ \\
\hline \multicolumn{6}{|l|}{ The Person } \\
\hline Face Time & $.86(.07)$ & $.84(.05)$ & .974280 & $.82(.07)$ & .875466 \\
\hline Hands time & $.48(.08)$ & $.63(.06)$ & .263651 & $.63(.06)$ & .262528 \\
\hline Actors & $1.17(.07)$ & $2.30(.52)$ & .029823 & $1.13(.06)$ & .995559 \\
\hline Sex & $1.09(.05)$ & $1.56(.08)$ & $.000011 * *$ & $1.15(.06)$ & .789434 \\
\hline Age & $26.20(.49)$ & $33.95(2.50)$ & .006696 & $27.11(1.61)$ & .927388 \\
\hline Face Frame & $.58(.07)$ & $.25(.03)$ & $.000636^{*}$ & $.56(.07)$ & .976553 \\
\hline Face Forward & $.65(.08)$ & $.40(.07)$ & .065255 & $.70(.07)$ & .893769 \\
\hline Eye Contact & $.31(.05)$ & $.14(.05)$ & .080525 & $.25(.06)$ & .713554 \\
\hline Makeup & $3.38(.26)$ & $1.52(.22)$ & $.000085 * *$ & $3.37(.36)$ & .999671 \\
\hline Dress & $3.22(.29)$ & $2.87(.26)$ & .625822 & $2.00(.25)$ & .008450 \\
\hline Smiling & $.08(.02)$ & $.15(.04)$ & .241325 & $.07(.02)$ & .972647 \\
\hline \multicolumn{6}{|l|}{ Speech/Audio } \\
\hline Mic Visibility & $.07(.05)$ & $.20(.07)$ & .154919 & $.00(.00)$ & .621165 \\
\hline Vocal Energy & $1.92(.14)$ & $3.56(.11)$ & $<.000001 * *$ & $3.17(.07)$ & $<.000001^{* *}$ \\
\hline Oral Wetness & $4.00(.20)$ & $3.04(.06)$ & $.000013 * *$ & $3.17(.12)$ & $.000109 * *$ \\
\hline Syllable Rate & $122.81(12.57)$ & $216.00(16.23)$ & $.000019 * *$ & $206.27(11.34)$ & $.000061 * *$ \\
\hline Word complexity & $1.36(.05)$ & $1.32(.02)$ & .637645 & $1.25(.02)$ & .031993 \\
\hline Loudness non-speech & $1.93(.18)$ & $3.44(.15)$ & $<.000001 * *$ & $2.73(.22)$ & .009040 \\
\hline Prop non-speech & $.59(.07)$ & $.65(.06)$ & .791217 & $.23(.05)$ & $.000135 * *$ \\
\hline Audio Roaming & $2.97(.29)$ & $1.03(.03)$ & $<.000001 * *$ & $1.00(0.00)$ & $<.000001 * *$ \\
\hline Dorsal Sound & $1.87(.28)$ & $1.00(.00)$ & .000745 & $1.00(0.00)$ & .000745 \\
\hline Proximity & $.51(.06)$ & $2.29(.38)$ & $.000006 * *$ & $1.05(.18)$ & .291180 \\
\hline Sound Pointing & $1.30(.16)$ & $1.00(.00)$ & .061805 & $1.00(.00)$ & .061805 \\
\hline Voicing & $66.09(3.26)$ & $32.81(1.78)$ & $<.000001 * *$ & $36.27(2.32)$ & $<.000001 * *$ \\
\hline
\end{tabular}




\begin{tabular}{|c|c|c|c|c|c|}
\hline Pitch & $2.34(.04)$ & $2.29(.03)$ & .524000 & $2.32(.02)$ & .800569 \\
\hline Pitch Variance & $.10(.01)$ & $.11(.01)$ & .930689 & $.10(.00)$ & .999984 \\
\hline Music & $1.33(.19)$ & $2.67(.33)$ & $.000423^{*}$ & $1.50(.26)$ & .872994 \\
\hline \multicolumn{6}{|l|}{ Topical content } \\
\hline Intimacy & $3.77(.21)$ & $1.23(.12)$ & $<.000001 * *$ & $1.83(.13)$ & $<.000001^{* *}$ \\
\hline Sing. Self-Ref. & $3.38(.60)$ & $3.38(.90)$ & .999972 & $7.03(1.09)$ & .017480 \\
\hline Plur. Self-Ref. & $.71(.22)$ & $1.37(.40)$ & .504667 & $2.03(.49)$ & .062205 \\
\hline Obs. Ref. & $3.00(.53)$ & $1.58(.51)$ & .362113 & $5.00(.91)$ & .121836 \\
\hline \multicolumn{6}{|l|}{ Setting } \\
\hline Frame Size & $.66(.06)$ & $1.72(.27)$ & $.000089^{* *}$ & $.68(.09)$ & .999646 \\
\hline Loc1 & $1.00(0.00)$ & $1.82(.30)$ & .015054 & $1.29(.20)$ & .58429 \\
\hline Loc2 & $2.47(.31)$ & $2.64(.29)$ & .890895 & $2.07(.21)$ & .561524 \\
\hline Loc3 & $1.00(0.00)$ & $2.61(.36)$ & $.000003^{* *}$ & $1.18(.15)$ & .829596 \\
\hline Lighting & $2.83(.14)$ & $3.07(.17)$ & .574310 & $3.00(.17)$ & .752670 \\
\hline
\end{tabular}

Note. The table lists the means (M) for each measure, the standard error of the means (SEM), and the $p$ values identifying significant differences between General control videos and ASMR videos, and Talkinghead control videos and ASMR videos. 

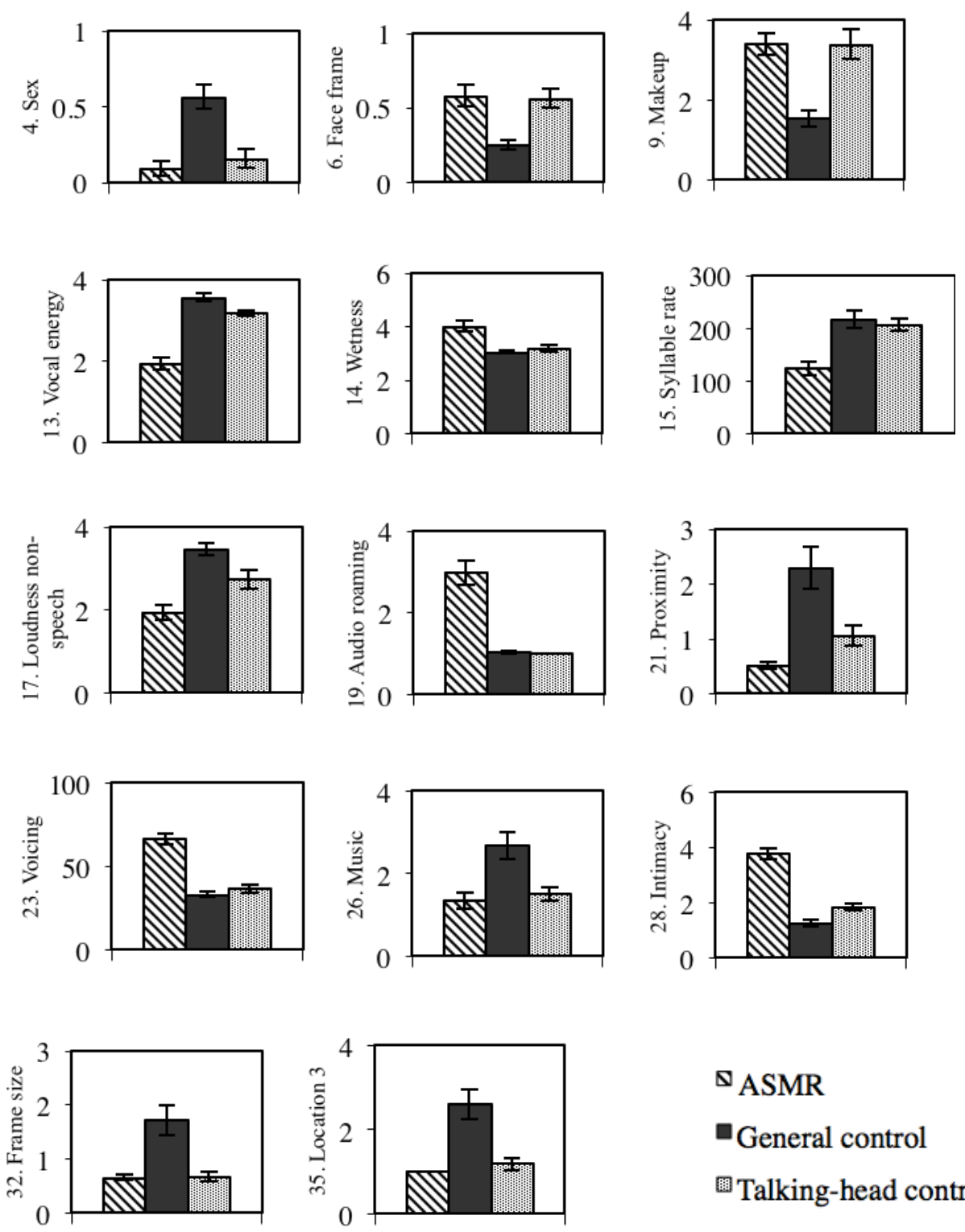

$\triangle$ ASMR

-General control

图Talking-head control

Figure 1. Graphical representation of measures with significant p-values. (Note: Each graph compares mean values for the ASMR videos, general control videos, and talking-head control videos. Error bars represent standard error for each mean. The associated number corresponds with measure number from Table 1, which details how the measure was collected.)

\section{Discussion}

In general, the results point to seven apparent themes. These include relaxation, quiet, proximity, intimacy, attraction, privacy, and movement. Relaxation is evident in the lower vocal energy, slower speaking rate, the quieter environment, and the greater use of pauses and whispering. Oral wetness (salivation) is associated with parasympathetic activation (rest \& digest response), which further connotes relaxation. Many of these same qualities are also characteristic of close physical proximity, close-up framing, and 
simply a quiet sound environment. The use of makeup and increased oral wetness cues are consistent with increased intimacy and attraction. Another theme appears to be the private setting. Finally, movement (especially the movement of sound) appears to also characterize ASMR videos in contrast to the various control videos.

\section{STUDY 2}

What makes a video an "ASMR" video is arguably less about the content of the video, and more about the responses of viewers. As a psychological phenomenon, our second study aims to characterize the common elements described by viewers responding to ASMR videos.

Recall that three earlier studies have surveyed ASMR viewers using a priori questions to gain insight into the viewer experience (Barratt and Davis, 2015; Fredborg et al., 2017; McErlean \& Banissy, 2017). In our exploratory study, we focused on unsolicited comments instead. Nevertheless, we will see that the results of our more open-ended approach provide converging evidence with these earlier studies.

For the purposes of this second study, we examined written comments and discussions found on various websites, including YouTube comments and reddit discussion forums. We also included the descriptions accompanying the uploaded videos, as well as the forum description (called "rules" on reddit).

In reviewing the comments, we specifically sought out comments related to physiology, etiology, psychology, and utility. That is, descriptions of physical symptoms, precipitating stimuli, subjective experiences, and functional uses of ASMR. Of course web comments are not necessarily representative; nor are comments independent responses. Not all viewers who experience ASMR from these videos will leave comments. Additionally, on the web, comments typically encourage further responses, sometimes reinforcing the original comment, or often disputing the comment. In this regard, web-originating comments differ considerably from the sorts of comments one might collect from an individually administered survey. These caveats notwithstanding, we nevertheless aimed to glean common characterizations related to physiology, etiology, psychology, and function.

With regard to sampling, we examined the comments for the same 30 videos used in the first sample of Study \#1. For each of the 30 videos, we examined the first 100 comments on YouTube. In addition, we examined the first 20 comments for the top 30 posts on Reddit.com/r/ASMR. Comments are commonly followed by discussion threads which respond to the initial comment. In order to increase data independence, we sampled only initial comments and ignored ensuing threads. Compared with YouTube threads, reddit threads tend to be shorter. Accordingly, we analyzed the "best" 20 comments (as labeled by reddit) from the top 30 threads. We first collected the primary comments; if there were fewer than 20 , we augmented the sample by collecting the first child comment beneath each initial comment until we achieved the sampling quota of 20 comments. Discussions of parodies were excluded as well as logistical posts discussing how to moderate the forum. We initiated sampling by collecting from the 25 all-time top posts, then continued with the top ASMR videos from this past year until we achieved the sampling quota of 30 posts.

In total, we assembled a sample of 3,600 comments. Individual comments were tagged with one or more of five tags: physiology (a comment related to a bodily state or bodily feeling), etiology (identification of an action or event in the video that was identified as the cause of some response), psychology (an introspective description of a cognitive or emotional state), and function (reports of how the viewer makes use of the video). A fifth category was simply tagged "interesting" if the comment was deemed intriguing, but not fitting into the other four categories. Note that a given comment could receive more than one of the five tags.

Comments were assigned to these five a priori categories twice, once by one of the experimenters, and a second time by an independent researcher not involved with the project. Roughly a third of the comments (1,331 - rater 1/ 1,016 - rater 2) were deemed to be irrelevant, tangential, or otherwise unsuited for further analysis. According to our a priori categories, 260/290 comments were deemed to relate to physiology, 968/690 comments related to etiology, 1,375/1,819 comments related to psychology, 174/224 comments related to function, and 229/411 comments were classified as otherwise "interesting." Comments within each of these five categories were then subjected to a content analysis using the pile sorting method commonly used in anthropology (De Munck, 2009). That is, each independent rater sorted the comments according to whatever categories seem salient given the contents of the comments. After independent sorting, both raters provided descriptive labels for each of their sorted categories. 


\section{Results}

On the basis of the two independent content analyses, an aggregate set of categories was created as shown in Tables 3-7. These categories were an effort to provide a superset of the two content analyses. This aggregate set of categories was created informally rather than employing any formal method. Each Table shows three columns. The first column identifies the agreed label for the comment category. The second column identifies the number of comments identified by each of the two raters that were deemed to fit in the category. The third column provides a sample comment.

Table 3. Study 2 categories which relate to Physiological Response.

\begin{tabular}{|c|c|c|}
\hline Label & Observations & Example \\
\hline Tingling & $163 / 145$ & major tingles all the way to my hands \\
\hline Localized response & $59 / 61$ & $\begin{array}{l}\text { Normally I always get tingles in the back of my } \\
\text { neck and my spine, this is the first time getting } \\
\text { them in the top of my head }\end{array}$ \\
\hline Sexual arousal & $7 / 38$ & I'm getting a tingling sensation in my balls. \\
\hline Shivers/chills & $11 / 8$ & Her voice gives me chills \\
\hline Goosebumps/cold & $8 / 8$ & I started to get goosebumps \\
\hline Tickling & $2 / 5$ & $\begin{array}{l}\text { your voice and the glass sounds make my spine } \\
\text { tickle }\end{array}$ \\
\hline Relaxed muscles & $1 / 5$ & $i$ cold feel the muscles in my back loosen \\
\hline Actually feeling the sensations & $0 / 6$ & $\begin{array}{l}\text { Omg did anyone else feel her breath go through } \\
\text { ur earphones?! }\end{array}$ \\
\hline Smelling things & $0 / 6$ & $\begin{array}{l}\text { Never has it happened before, but I actually smelt } \\
\text { herbs. What is this sorcery? }\end{array}$ \\
\hline Feel sick & $2 / 3$ & For some weird reason I started feeling nauseous \\
\hline Sweating & $2 / 1$ & $\begin{array}{l}\text { This is so weird, my palms are sweating and my } \\
\text { shoulders are tingling }\end{array}$ \\
\hline Vibrations & $2 / 0$ & $\begin{array}{l}\text { I could feel the vibrations all over my head, that's } \\
\text { so awesome!! }\end{array}$ \\
\hline Eyes watering & $1 / 1$ & $\begin{array}{l}\text { while I was hearing that brush sound my eyes } \\
\text { started watering like crazy }\end{array}$ \\
\hline Stomach drop & $0 / 1$ & $\begin{array}{l}\text { I dont get tingles, my stomach just has a slight } \\
\text { drop feeling like on a swing. }\end{array}$ \\
\hline Pain & $0 / 1$ & For some reason this hurts my nose \\
\hline Weak knees & $1 / 0$ & these sounds to make my knees feel weak \\
\hline Teeth & $1 / 0$ & Is it normal that I get freeky feelings in my teeth? \\
\hline Pins and needles & $0 / 1$ & I was just getting pins and needles. \\
\hline
\end{tabular}


Table 4. Study 2 categories which relate to etiology.

\begin{tabular}{|c|c|c|}
\hline Label & Observations & Example \\
\hline Voice (general) & $103 / 122$ & $\begin{array}{l}\text { Your voice is just so beautiful, it lulls me off to } \\
\text { sleep. }\end{array}$ \\
\hline Didn't work & $0 / 121$ & $\begin{array}{l}\text { I have some questions because it didn't work for } \\
\text { me. }\end{array}$ \\
\hline Detracting aspect & $0 / 88$ & $\begin{array}{l}\text { I do like your voice however i think you talk too } \\
\text { quickly for it to be relaxing. You sound rushed. }\end{array}$ \\
\hline Physically attractive person & $87 / 0$ & wow you're beautiful. \\
\hline $\begin{array}{l}\text { Certain spoken sounds (sk, ch, } \\
\text { ts, tk, etc) }\end{array}$ & $40 / 23$ & $\begin{array}{l}\text { I really liked the sksksk, idk why but it makes my } \\
\text { ears feel so good!! Thanks for the video }\end{array}$ \\
\hline Brushing & $32 / 24$ & Love the sound of the brushing. \\
\hline $\begin{array}{l}\text { High quality sound (binaural, } \\
\text { headphones) }\end{array}$ & $43 / 13$ & God Bless $3 d$ Mics \\
\hline $\begin{array}{l}\text { Buzzing/electric noises (white } \\
\text { noise) }\end{array}$ & $25 / 28$ & $\begin{array}{l}\text { it's good to know that there are a lot of crazy } \\
\text { people like me who love the hair dryer sounds and } \\
\text { other vacuuming sounds to get some sleep }\end{array}$ \\
\hline Whispers & $28 / 22$ & $\begin{array}{l}\text { Your whispering definitely sends triggers down my } \\
\text { spine and I hadn't even begun the full video. }\end{array}$ \\
\hline Tapping & $27 / 19$ & $\begin{array}{l}\text { Some triggers are insanely effective (finger } \\
\text { tapping imo). }\end{array}$ \\
\hline Role Play & $37 / 8$ & Best ASMR spa role play... thank you \\
\hline Too much talking is bad & $44 / 0$ & $\begin{array}{l}\text { are there any videos with more sounds and not so } \\
\text { much talking? As soon as I begin appreciating the } \\
\text { tapping, bristles, etc.... a voice interupts it and the } \\
\text { purpose is lost }\end{array}$ \\
\hline Visuals (general) & $13 / 29$ & The lighting and background for this was perfect \\
\hline Sounds (general) & $33 / 9$ & $\begin{array}{l}\text { Oh I love them sounds you make I find them } \\
\text { relaxing. }\end{array}$ \\
\hline Water noises & $20 / 15$ & $\begin{array}{l}\text { I really enjoyed all of these sounds. The spray } \\
\text { bottle especially... }\end{array}$ \\
\hline Too loud is bad & $12 / 23$ & $\begin{array}{l}\text { I loved the sounds, but for my taste the background } \\
\text { noise was relatively loud. }\end{array}$ \\
\hline $\begin{array}{l}\text { Paper noises (writing, cutting, } \\
\text { crinkling) }\end{array}$ & $22 / 12$ & $\begin{array}{l}\text { I found my trigger within the first few mins.. that } \\
\text { paper, wow! }\end{array}$ \\
\hline Non-American accent & $31 / 0$ & I love your accent, I'm jealous. \\
\hline Ads are bad & $29 / 0$ & Loud ads should be banned on ASMR videos \\
\hline Watching a certain person & $16 / 13$ & $\begin{array}{l}\text { Maybe I'm too used to gentle whispering that I } \\
\text { don't like any other Asmr }\end{array}$ \\
\hline Mouth noises (eating, chewing) & $17 / 12$ & $\begin{array}{l}\text { I go tingle crazy when someone smacks their lips } \\
\text { when they talk.. strange. }\end{array}$ \\
\hline Hair or face touching in real life & $14 / 13$ & $\begin{array}{l}\text { I thought I was the only one totally addicted to } \\
\text { other people touching my hair lol }\end{array}$ \\
\hline Playing with hair & $26 / 0$ & $\begin{array}{l}\text { I could watch you braid hair all day, it's so } \\
\text { relaxing! }\end{array}$ \\
\hline High quality videos & $24 / 0$ & $\begin{array}{l}\text { couldnt fall asleep with this video because } i \text { was } \\
\text { just so fascinated by the special effects }\end{array}$ \\
\hline Eyes & $21 / 0$ & $\begin{array}{l}\text { Your eyes are hypnotizing. Feel like youre actually } \\
\text { looking at me through the phone }\end{array}$ \\
\hline
\end{tabular}




\begin{tabular}{|c|c|c|}
\hline Label & Observations & Example \\
\hline Specific viewing conditions & $21 / 0$ & I use Screen Dimmer on my Android. Love it. \\
\hline $\begin{array}{l}\text { Creative/intellectually } \\
\text { stimulating }\end{array}$ & $19 / 0$ & $\begin{array}{l}\text { This is my favorite ASMR video on YT, it's so } \\
\text { imaginative and clever with the ideas you } \\
\text { referenced. }\end{array}$ \\
\hline Music & $12 / 7$ & $\begin{array}{l}\text { please do more music / soft voice/whispering vids. } \\
\text { I literally cannot get enough! They make me so } \\
\text { happy! :) }\end{array}$ \\
\hline Hands & $8 / 10$ & $\begin{array}{l}\text { The best Asmr video ever [(y)] I loved the hand } \\
\text { brushing! }\end{array}$ \\
\hline Bob Ross & $17 / 0$ & $\begin{array}{l}\text { Bob Ross used to set my ASMR off back before I } \\
\text { had any idea what it was. }\end{array}$ \\
\hline Watching playing with ears & $12 / 4$ & $\begin{array}{l}\text { the ear massage really helped me relax, more of } \\
\text { the same sound please!!! }\end{array}$ \\
\hline Feathers & $8 / 7$ & The feathers are AMAZING \\
\hline Gentle, slow movements & $15 / 0$ & Tap slower please it feels rushed \\
\hline Soft Speaking & $15 / 0$ & $\begin{array}{l}\text { This was great! It gave me brain tingles! I love the } \\
\text { soft way you talk }\end{array}$ \\
\hline Clicking & $9 / 6$ & I like the sound of a computer mouse clicking \\
\hline Scratching & $6 / 5$ & I think my trigger was the book scratching! \\
\hline Birds & $4 / 7$ & I like the bird sounds in the background. \\
\hline Sound problems & $0 / 11$ & Please speak louder, i can't understand anything. \\
\hline Too fast is bad & $0 / 10$ & Ifelt agitated when you kinda rushed it \\
\hline Too quiet is bad & $9 / 0$ & Please speak louder, i can't understand anything. \\
\hline Glass & $0 / 9$ & $\begin{array}{l}\text { The glass tapping was beautiful and sprung my } \\
\text { trigger of tingglieness [:-)] }\end{array}$ \\
\hline Breathing (and blowing) & $5 / 4$ & $\begin{array}{l}\text { Best asmr video in YouTube. The whispering and } \\
\text { the breathing in the ear kills me right away }\end{array}$ \\
\hline Artist's mouth or smile & $8 / 0$ & $\begin{array}{l}\text { the sounds in this vid are good but I get the tingles } \\
\text { from your smile also }\end{array}$ \\
\hline Unintentional & $8 / 0$ & $\begin{array}{l}\text { I watching unboxing videos. Unintentional ASMR } \\
\text { is the most intense for me. }\end{array}$ \\
\hline Close proximity & $7 / 0$ & I loved that you came close to the screen \\
\hline $\begin{array}{l}\text { Harsh sounds (rustling, } \\
\text { crunching) }\end{array}$ & $0 / 6$ & Please do turning a page slowly and noisily \\
\hline Movement & $6 / 0$ & $\begin{array}{l}\text { my trigger seems to be book scratching...or most } \\
\text { calm hand movements. }\end{array}$ \\
\hline Fabric noises & $6 / 0$ & $\begin{array}{l}\text { and the shirt you wore for this was the icing on the } \\
\text { cake, such good soft crinkles. }\end{array}$ \\
\hline Intentional & $5 / 0$ & $\begin{array}{l}\text { I usually can't stand intentional videos but this } \\
\text { was FANTASTIC. }\end{array}$ \\
\hline Only visual triggers & $4 / 0$ & $\begin{array}{l}\text { Am I the only one who watches this video with the } \\
\text { sound off? }\end{array}$ \\
\hline Smoke/Steam & $4 / 0$ & Love that steam! \\
\hline Smells & $3 / 1$ & I was surprised that I got tingles from the lavender \\
\hline
\end{tabular}




\begin{tabular}{|c|c|c|}
\hline Label & Observations & Example \\
\hline Gloves & $0 / 3$ & THE GLOVESSS \\
\hline Only females & $3 / 0$ & $\begin{array}{l}\text { for some reason only Asmr videos by girls relaxes } \\
\text { me... is this normal? }\end{array}$ \\
\hline Real life sound bath & $3 / 0$ & $\begin{array}{l}\text { This women in LA gives "sound baths" aka real } \\
\text { life ASMR. }\end{array}$ \\
\hline Crunching & $3 / 0$ & $\begin{array}{l}\text { its like the feeling } i \text { get when } i \text { hear cars or trucks } \\
\text { driving over gravel. }\end{array}$ \\
\hline Instructional simple task & $2 / 0$ & Watching other people performing simple tasks \\
\hline Bottle opening & $0 / 2$ & $\begin{array}{l}\text { Their are several triggers for me here, the sound } \\
\text { of bottles being opened, and the clinking of glas }\end{array}$ \\
\hline Pebbles & $0 / 2$ & $\begin{array}{l}\text { The pebble one made me feel a numbing tingly } \\
\text { feeling on my scalp }\end{array}$ \\
\hline Discomfort & $1 / 1$ & $\begin{array}{l}\text { Idk why but I can only experience tingles while } \\
\text { experiencing very slight discomfort. }\end{array}$ \\
\hline Feeling through headphones & $0 / 1$ & $\begin{array}{l}\text { It feels like she is right next to you with } \\
\text { headphones }\end{array}$ \\
\hline Counting & $1 / 0$ & $\begin{array}{l}\text { I love it when you count in your videos. You could } \\
\text { count to a million and I would get tingles all the } \\
\text { way through. }\end{array}$ \\
\hline
\end{tabular}


Table 5. Study 2 categories which relate to Psychological Response.

\begin{tabular}{|c|c|c|}
\hline Label & Observations & Example \\
\hline General positive reaction & $456 / 400$ & My all-time favorite ASMR video. \\
\hline Love/admiration for the artist & $119 / 427$ & She is just amazing! \\
\hline Calm/relaxation & $198 / 248$ & Most relaxing thing ever:) \\
\hline Gratitude & $121 / 251$ & Thank you for doing these they help so much! \\
\hline Sleepy & $100 / 95$ & ifell asleep when waching this \\
\hline Confusion & $48 / 103$ & what is this stuff? I don't get it... \\
\hline Weird/creepy & $68 / 83$ & Ifeel violated and creeped out. \\
\hline Favorite ASMR & $0 / 102$ & My all-time favorite ASMR video. \\
\hline Can't get it to work & $48 / 0$ & ASMR doesn't work for me \\
\hline Nostalgia & $9 / 35$ & it reminds me my childhood. \\
\hline Comforted/cared for & $26 / 11$ & $\begin{array}{l}\text { You make feel so cozy and comforted with this, } \\
\text { thank you. }\end{array}$ \\
\hline Misophonia/irritation & $34 / 9$ & $\begin{array}{l}\text { I HATE and I mean HATE the sound of the lips and } \\
\text { breathing you make when you whisper etc. This is } \\
\text { ear rape for me. }\end{array}$ \\
\hline Sexual & $36 / 0$ & This does sound so sexual. \\
\hline Anxious/scared & $29 / 0$ & $\begin{array}{l}\text { ASMR is supposed to be relaxing? It gives me a } \\
\text { heart attack }\end{array}$ \\
\hline Laughter & $28 / 0$ & LOL! I laughed out loud. \\
\hline Drug like & $0 / 21$ & this is my kind of getting high and relaxing... \\
\hline Feel like its real & $20 / 0$ & $\begin{array}{l}\text { The latex gloves one is like having someone put } \\
\text { their fingers in your ears }\end{array}$ \\
\hline Hate interruptions & $0 / 17$ & $\begin{array}{l}\text { I hate it how you go to listen to an ASMR video, } \\
\text { and then some ad comes on with music loud enough } \\
\text { to burst your eardrums. }\end{array}$ \\
\hline Surprise & $0 / 17$ & Wow! sksksksksk took me by surprise... LOVED it! \\
\hline $\begin{array}{l}\text { Happiness that more people } \\
\text { experience it }\end{array}$ & $13 / 0$ & $\begin{array}{l}\text { OMG I now know that I have ASMR!!! THANK } \\
\text { YOU!!!! GREAT TO BE PART OF THE } \\
\text { COMMUNITY }\end{array}$ \\
\hline Ease anxiety & $10 / 0$ & $\begin{array}{l}\text { I was having some anxiety but this video definitely } \\
\text { calmed me down and helped }\end{array}$ \\
\hline Crazy & $9 / 0$ & $\begin{array}{l}\text { it's good to know that there are a lot of crazy } \\
\text { people like me who love the hair dryer sounds and } \\
\text { other vacuuming sounds to get some sleep }\end{array}$ \\
\hline Not frisson & $3 / 0$ & $\begin{array}{l}\text { NOT TO BE CONFUSED WITH MUSIC BASED } \\
\text { TINGLES/SHIVERS. Those are called frisson and } \\
\text { can be discussed in/r/frisson }\end{array}$ \\
\hline
\end{tabular}


Table 6. Study 2 categories which relate to Function.

\begin{tabular}{|c|c|c|}
\hline Label & Observations & Example \\
\hline Sleep & $79 / 118$ & I usually listen to MassageASMR before bed. \\
\hline Easy anxiety & $25 / 29$ & $\begin{array}{l}\text { I have horrible anxiety and your videos always calm } \\
\text { me down. Thank you so much. }\end{array}$ \\
\hline Relax/Unwind & $14 / 36$ & My go-to relaxation video \\
\hline While doing Work & $16 / 15$ & $\begin{array}{l}\text { I'm doing some boring paperwork right now and } \\
\text { this video is helping me so much! }\end{array}$ \\
\hline Ease pain/sickness & $15 / 15$ & $\begin{array}{l}\text { Thank you for this video. I listen and watch this at } \\
\text { night when I am in pain and can't sleep. It relaxes } \\
\text { me enough to ease my fibromyalgia. }\end{array}$ \\
\hline Insomnia & $15 / 0$ & $\begin{array}{l}\text { This video has cured my problem with not being } \\
\text { able to sleep at night. THANK YOU. }\end{array}$ \\
\hline For children & $7 / 8$ & $\begin{array}{l}\text { This has relaxed my } 6 \text { month old since birth. } \\
\text { Thanks! }\end{array}$ \\
\hline Relax muscles & $3 / 0$ & $\begin{array}{l}\text { I think it's honestly helped with tension in my } \\
\text { shoulders! }\end{array}$ \\
\hline When sad & $0 / 3$ & $\begin{array}{l}\text { When I'm feeling down or just need to relax (i.e. } \\
\text { now, when I have a fever) I watch or rather listen to } \\
\text { this video. }\end{array}$ \\
\hline
\end{tabular}

Table 7. Study 2 comments which were otherwise interesting.

\begin{tabular}{|c|c|c|}
\hline Label & Observations & Example \\
\hline Requests & $65 / 149$ & $\begin{array}{l}\text { I have a request. Could you please do whispering } \\
\text { while painting your nails? Thanks! }\end{array}$ \\
\hline Frequent usage & $45 / 166$ & I love this vid, can't stop watching it \\
\hline Theories & $15 / 50$ & $\begin{array}{l}\text { to me they are emotion strings they trigger parts of } \\
\text { life that where maybe left out that you longed for .... } \\
\text { My theory anyways.. }\end{array}$ \\
\hline First ASMR ever seen & $0 / 37$ & $\begin{array}{l}\text { Oohh this is my very first AMSR video! Thanks you } \\
\text { soooo much }\end{array}$ \\
\hline Extreme love for the artist & $30 / 0$ & $i$ want to marry this girl!! \\
\hline Addiction/tolerance & $20 / 0$ & $\begin{array}{l}\text { Dude, I am so addicted to your videos that I'm } \\
\text { getting resistant ASMR. }\end{array}$ \\
\hline $\begin{array}{l}\text { Places in the world its listened } \\
\text { to }\end{array}$ & $19 / 0$ & I am Korean. This is so nice! Thanks \\
\hline "Imagine" statements & $12 / 0$ & $\begin{array}{l}\text { If you were to put a screamer at the end of a } \\
\text { video........... }\end{array}$ \\
\hline Gender/sexuality Theory & $0 / 9$ & $\begin{array}{l}\text { The interesting thing about ASMR is the } \\
\text { undoubtedly sexual element, whether that gets } \\
\text { acknowledged or not. }\end{array}$ \\
\hline Sense of community & $8 / 0$ & Hi! Nice to be a part of this community. \\
\hline With drug usage & $8 / 0$ & smoke weed and listen to ASMR =) \\
\hline Association with Asperger's & $7 / 0$ & $\begin{array}{l}\text { Have Asperger's and am obsessed with ASMR. } \\
\text { There is } 100 \% \text { a connection for me. }\end{array}$ \\
\hline
\end{tabular}




\section{Discussion}

As an exploratory study, we did not have any a priori hypotheses to test. Once again, the goal is simply to provide a reasonably representative characterization of ASMR. Based on the collected comments, we distilled any common themes.

Regarding physiology, very few comments described specific somatic or physiological symptoms. The most common physical description was a feeling of "tingling." Depending on the coder, between 145 and 163 comments were deemed to include a "tingling" description. The next most common comment group for physical symptoms pointed to a specific somatic location (59/61 comments). Common locations included the back of the neck and spine, and the back of the head. To a lesser extent viewers identified shoulders and arms. These findings reinforce Barratt and Davis's (2015) surveyed results, that the physiological response consists of a tingling sensation most often originating at the back of the head and neck. The third most common comment group was sexual arousal (7/38 comments). A much smaller number of comments (8/11 comments) identified feelings of shivers or chills. Eight comments specifically identified goosebumps.

Regarding etiology, it was common for commentators to describe what "does it" and what "doesn't do it" for them. The comments here spanned a wide variety of circumstances. Some comments relate to visual aspects, others to auditory aspects. Comments pointed to both important "triggers" of the ASMR response, and also pointed to aspects that suppressed or "ruined" the effect. As might be expected, comments revealed a number of disagreements. Some of these disagreements led to independent threads where people would effectively celebrate that they had found people of like experience, while acknowledging that other ASMR enthusiasts appear not to have the same experience. The most popular category was the quality of the voice. Common preferences were for whispered or soft-spoken voice. Comments often identified particular speech sounds, most notably sibilants ("s", "sh," and "sk"). Other popular sounds included breathing, chewing, and eating sounds.

Non-vocal triggers included brushing, buzzing, and tapping sounds, clicking or scratching, water noises, and the sound of hair being combed or brushed. Viewers expressed appreciation for high quality sound recording as well as good visual production. Both ASMR producers and ASMR viewers frequently note the importance of headphone listening, and binaural recording. Complaints were often voiced that the sound was too loud, too fast, (or less commonly) too quiet. Frequent complaints focused on interruptions due to YouTube advertising, especially when the advertising resulted in dramatic increases in loudness.

Regarding visual triggers, the most common comment related to the visual attractiveness of the ASMR actor. Expressions of appreciation included the proximity of the actor to the camera ("I love that you came close to the screen"). A few viewers note that they mute the audio and simply enjoy watching the visual. These etiological findings converge with prior surveyed results. Barratt and Davis (2015) identified whispering, attention, crisp sounds, and slow movements as common triggers. McErlean and Banissy (2017) identified whispering, finger tapping, hair brushing, various role-playing scenarios, and eating to be popular triggers. This open-ended approach helps to illustrate the immense potential for variety in stimuli used to evoke ASMR in viewers.

Regarding psychology, the single most important observation is that the experience of ASMR is regarded as enjoyable or pleasurable. As might be imagined, commentaries polarize into praise and criticism. Positive comments include expressions of love or appreciation for the artist, appreciation of the calming or relaxing effect of the video, feeling comforted or cared-for, appreciation of the video's ability to induce sleepiness, and expressions of nostalgic appreciation, such as reminding a viewer of how their mother would speak to them as a child. Negative comments indicate that ASMR is clearly experienced by only a subset of the population. The most popular negative comments include expressions of confusion by non-ASMR individuals. For these viewers, ASMR videos seem odd-ball, weird, or (in some cases) "creepy." Negative comments include expressions of how the video makes the viewer feel anxious, scared, or engenders misophonia. Finally, negative comments include complaints (by ASMR fans) that a particular video fails to work for them.

Regarding function, the most commonly reported "use" for ASMR videos is to facilitate falling asleep. Other commonly claimed functions include easing anxiety, inducing a relaxed state, and helping to unwind. In addition, comments indicate that ASMR videos are used to deal with insomnia, to calm infants, and (in several cases) to ease pain or sickness. For example, one viewer reportedly used ASMR videos to deal with pain following a dental operation, and another viewer reported using ASMR videos to better handle fibromyalgia. Finally, viewers report using ASMR videos while working, such as doing homework, 
or dealing with paperwork. These results directly align with surveyed results, indicating that ASMR videos are most commonly used for relaxation, sleep-aid, and to ease stress (Barratt \& Davis, 2015; McErlean \& Banissy, 2017).

Among the comments grouped in the "interesting" category, some viewers reported a sense of being addicted to the videos. Frequent viewers would sometimes report a feeling of increasing tolerance or reduced effect. Eight comments explicitly noted enjoying viewing ASMR videos in conjunction with recreational drug use, the most commonly reported drug being marijuana. One discussion thread speculated about the relationship between ASMR and Asperger's syndrome, noting anecdotally that people with Asperger's may be more likely to enjoy ASMR. Although anecdotal and speculative, such observations are consistent with sensory sensitivity thought to be symptomatic of Asperger's (e.g., Baron-Cohen, Ashwin, Ashwin, Tavassoli, \& Chakrabartia, 2009). It was common for ASMR fans to express appreciation for the sense of community experienced through the online groups.

\section{GENERAL DISCUSSION}

Autonomous sensory meridian response (ASMR) is a recently popular phenomenon whose purpose-created videos have attracted millions of viewers, including a large dedicated community of appreciative fans. In light of study \#1, ASMR videos exhibit a number of distinctive characteristics. They typically involve private scenes in which an attractive female actor engages in quiet role-playing activities, speaking in a relaxed, low-energy voice, sometimes whispering. With respect to both audio and visual stimuli, the videos exhibit considerable warmth or intimacy, occasionally exhibiting some flirtatious elements but otherwise devoid of overt sexuality.

In light of study \#2, viewers of ASMR videos appear to readily polarize into two different groups. ASMR fans find the videos relaxing and enjoyable, sometimes intensely pleasurable. Non-fans report finding the videos weird, odd-ball, and stressful. Among ASMR fans, pleasant physiological responses include a tingling sensation, especially around the back of the head and the neck. These positive feelings appear to be triggered by quiet voice, associated intimate sounds, as well as perhaps visual close up. ASMR fans report using the videos to induce relaxation and as an aid for sleep.

Future investigations of ASMR might consider two questions. First, what are the personal or experiential attributes that distinguish ASMR fans from non-fans? Second, detailed examination of the physiological responses is warranted. These might include topical and metabolic measures as well as further imaging of the central nervous system during ASMR experiences.

\section{Relationship Between ASMR and Frisson}

Ultimately, the most compelling question is one of hedonics: how is it that ASMR is able to evoke pleasure? The similarity of ASMR to frisson suggests that the two phenomena might share a common source.

For researchers interested in the phenomenon of frisson (whether musically-induced or not), ASMR raises something of a paradox. On the one hand, the physiological symptoms of ASMR strongly resemble the classic symptoms of frisson. Both involve phenomenologically pleasurable pilomotor activation (Blood \& Zatorre, 2001; Panksepp, 1995; Sloboda, 1991). Historically, "pleasurable goosebumps" has provided the principal operational definition of frisson -- implying that ASMR might be regarded as a type of frisson. On the other hand, many people who experience ASMR also report experiencing frisson in response to music, and several aficionados insist that ASMR experiences differ qualitatively from frisson (Collins, 2012; Higham, 2014).

One apparent difference between ASMR and frisson is that ASMR responders are more likely to describe the topical (skin-related) response as a "tingling" sensation rather than as goosebumps. In addition, tingling feelings from ASMR are more likely to be reported as sustained and subdued in comparison to frisson (Collins, 2012). Nevertheless, pilomotor activation is common to both experiences, and the topical distribution (neck, shoulders, head) appears to be virtually identical in both experiences (Barratt \& Davis, 2015). The most notable difference between the two experiences is the contrasting nature of the stimuli. In the case of musically-induced frisson, extant research points to a cluster of acoustical/musical properties. These include loud sounds, volume or extensity (many sound sources), low pitch, approaching sounds (crescendos), infrasound, scream-like sounds, and surprising (unexpected) sounds (see Huron \& Margulis, 
2010 for a review). As we have seen, the stimuli associated with ASMR are much quieter, more proximate, are more likely to entail sounds behind the listener, and involve more human vocalizing, especially whispered speech. In short, the sounds associated with ASMR appear much more intimate in character.

This raises the question of how two broadly similar responses might arise from such contrasting stimuli. Theories of music-induced frisson have been reviewed in Huron and Margulis (2010). The most developed theory is that proposed by Huron (2006). Inspired by McGraw (1999, McGraw \& Warren, 2010), Huron proposed that affective contrast can lead to marked pleasurable experiences. That is, a negatively valenced response (such as fear) can be suppressed resulting in an overall positively valenced effect. A classic example is provided by the surprise party in which an unexpected surprise produces momentary startle or even panic, which is then suppressed due to cognitive appraisal of the innocuousness of the situation. As long ago as 1757, Burke proposed that sublime experiences entail some element of fear. For example, Burke defined "awe" as "wonder tinged with fear." Expanding on Burke's observations, Huron (2006) noted that the pilomotor response (goosebumps) is a classic fear response. All mammals (including humans) commonly respond to fear-inducing stimuli by hair-raising, especially around the neck and shoulder regions. Similarly, breath-holding is a component of tonic immobility which characterizes the fear-induced "freeze" response. Huron proposed that the suppression of fear results in positively valenced breath-holding, commonly associated with the experience of awe.

Finally, the idea that suppressing fear can be pleasurable is evident in the two most popular theories of laughter. Both Vilayanur Ramachandran's false alarm theory (1998) and McGraw and Warren's benign violation theory (2010) posit the idea that laughter is provoked by an initially alarming or fearinducing stimulus that is subsequently assessed as inconsequential.

Huron (2006) argued that the suppression of fear underlies all three responses: frisson, awe, as well as laughter. Following Burke, Huron proposed a "suppressed fear" theory, whose basic claim is that pleasure is evoked when a stimulus activates subcortical structures associated with fear (notably the amygdalae) which are then inhibited or suppressed due to cognitive (cortical) appraisal that the stimulus is innocuous.

In the case of classic music-induced frisson, common stimulus properties (loud, voluminous, low pitch, approaching, infrasound, scream-like timbres, and surprise) are all plausibly-linked to alarm, and so would be expected to contribute to subcortical activation of fear.

What is missing from this account is the recognition that loud/surprising/scream-like sounds are not the only way to evoke fear. There are innumerable ways to evoke anxiety, fear, or panic (Marks, 1987). Common sources of fear include fear of pain, fear of death, fear of hunger, cold, heat, injury, disease, excrement, sexual assault, social threat, embarrassment, loss of financial resources, loss of friends, being lost, physical confinement, confusion, blindness, etc.

As we have seen, ASMR is evoked by rather different sorts of stimuli than the prototypical musical frisson stimulus. Most notably, ASMR videos are characterized by high levels of intimacy and proximity. Proximity is known to be an important physical cue that can evoke fear or panic. Hearing a fly buzzing around a room, listeners typically do not experience high arousal levels. However, should the fly buzz in close proximity to one's face or ears, the result can lead to a considerable increase in physiological arousal. Nor is this effect limited to insects. A person whispering quietly in your ear is more likely to raise arousal levels than a person speaking in a louder voice from across a room.

In general, there are excellent reasons for an animal to become attentive to close proximity, especially when the other individual is a stranger. The phrase "violation of personal space" highlights the sense of the potential peril or danger associated with close physical proximity. Although sexual intimacy is rarely explicit in ASMR videos, when present, implications of sexual intimacy can be both compelling as well as threatening.

If, as conjectured, ASMR and frisson begin as subcortical fear responses, then one might expect ASMR and frisson responders to exhibit greater sensitivity to threat or danger compared with nonresponders. Extant studies of both ASMR and frisson do indeed show the expected personality traits. For example, Nusbaum (2012) showed that scoring significantly higher on neuroticism and openness in the five-factor personality assessment had significant main effects on the occurrence of chills from music. Others have similarly shown that openness to experience is a strong predictor of experiencing frisson (Colver \& El-Alayli, 2016; Nusbaum \& Silvia, 2011). In their study of ASMR responders, Fredborg et al. (2017) similarly found that ASMR-responders score significantly higher on neuroticism and openness. The disposition towards neuroticism is consistent with a greater sensitivity to threat. That is, both ASMR and 
frisson experiences are more likely to occur among those who are more vigilant and more prone to perceive danger.

In their review of the ASMR literature, del Campo \& Kehle (2016) suggest that ASMR might be a milder form of frisson. Note that this suggestion might account for the tendency to describe the topical effects as a "tingling" sensation rather than as goosebumps.

Accordingly, we might propose the following interpretation of ASMR and it's relationship to frisson. Like frisson, we suggest that ASMR might achieve its emotional power by evoking unconscious subcortical fear that is then cognitively assessed as inconsequential. However, the fear evoked by ASMR stimuli arises through the mechanisms of proximity and intimacy rather than via acoustic bombast. In both cases, the pilomotor response is symptomatic of classic fear, and in both cases the experience of pleasure implicates positive cortical assessment posited as characteristic of suppressed fear theory. In short, the physiological and hedonic responses are similar, even though the precipitating stimuli differ notably.

If this interpretation is correct, it suggests that ASMR might be reasonably regarded as a type of frisson. We need only explain why many of those who experience ASMR insist that it is qualitatively different from frisson. Misattribution theory provides a plausible explanation. In general, stimuli are cognitively more salient than responses; moreover, responses tend to be attributed to the stimuli. In the seminal work on misattribution, young men were induced to experience mild vertigo, but in the presence of a beautiful woman the men misconstrued their response as enfatuation for the woman (Dutton \& Aron, 1974). Said another way, people are generally more attentive to sights and sounds, and less attentive to internal affective states. Two contrasting stimuli might evoke similar experiences, but the perceptual contrast holds greater psychological weight. Consequently, it makes sense that ASMR fans might focus on the differences that distinguish ASMR stimuli from the sorts of stimuli commonly described in the frisson literature.

Finally, one further person-related variable deserves mention. In certain cases, listeners can experience sound-induced anger ("misophonia," which literally translates as "hatred of sound"). For example, Schröder, Vulink, and Denys (2013) have documented how some listeners intensely dislike eating sounds (such as chewing) or the sound of tapping. Moreover, in a large-scale study of misophonia, Rouw and Erfanian (2017) found that 49 percent of listeners who experience misophonia are also prone to experience ASMR. This suggests that ASMR and misophonia share a heightened sensitivity to certain sounds, especially sounds that might induce forms of irritation, including anger (misophonia) and fear. Kumar et al. (2017) recently conducted an fMRI study on misophonic individuals which indicated that these individuals attribute abnormal salience to particular sounds, based on abnormal functional connectivity of the anterior insular cortex (AIC). AIC activity mediated both the increased heart rate and galvanic skin responses of individuals to trigger sounds, which are both classic fear responses (Kumar et al., 2017). Future investigation into ASMR may wish to take into consideration and build off past work conducted on misophonia as the two phenomena may very well be related.

\section{ACKNOWLEDGEMENTS}

Special thanks to Susan Meyer, Stephne Rasiah, and Dr. Johanna Devaney for their assistance with completion of this project. Additional thanks to the Ohio State University URO for providing funding. This article was copyedited by Tanushree Agrawal and layout edited by Kelly Jakubowski.

\section{NOTES}

[1] Correspondence can be addressed to: College of Medicine, 2237 Parkwood alexsandra.kovacevich@rockets.utoledo.edu.
Alexsandra Kovacevich, The University of Toledo Avenue Apartment 2A, Toledo, Ohio 43620, 


\section{REFERENCES}

Baron-Cohen, S., Ashwin, E., Ashwin, C., Tavassoli, T., \& Chakrabarti, B. (2009). Talent in autism: hypersystemizing, hyper-attention to detail and sensory hypersensitivity. Philosophical Transactions of the Royal Society B: Biological Sciences, 364 (1522), 1377-1383. https://doi.org/10.1098/rstb.2008.0337

Barratt, E.L., \& Davis, N.J. (2015). Autonomous sensory meridian response (ASMR): A flow-like mental state. PeerJ, 3 (851). https://doi.org/10.7717/peerj.851

Blood, A. J., \& Zatorre, R. J. (2001). Intensely pleasurable responses to music correlate with activity in brain regions implicated in reward and emotion. Proceedings of the National Academy of Sciences, 98, 11818-11823. https://doi.org/10.1073/pnas.191355898

Burke, E. A. (1757/1759). A Philosphoical Inquiry into the Origin of Our Ideas of the Sublime and Beautiful. London: Dodsley.

Cheadle, H. (2012). ASMR, the good feeling no one can explain. Vice. Posted July 31, 2012. Accessed 13 October 2014. Retrieved from https://www.vice.com/en_us/article/gqww3j/asmr-the-good-feeling-noone-can-explain

Collins, S. T. (2012). Why music gives you the chills. Posted 10 September 2012. Accessed 9 August 2017. Retrieved from http://www.buzzfeed.com/theseantcollins/why-music-gives-you-the-chills-7ahd

Craig, D. G. (2005). An exploratory study of physiological changes during 'chills' induced by music. Musicae Scientiae, 9, 273-287. https://doi.org/10.1177/102986490500900207

del Campo, M. A., \& Kehle, T. J. (2016). Autonomous Sensory Meridian Response (ASMR) and Frisson: Mindfully Induced Sensory Phenomena That Promote Happiness. International Journal of School \& Educational Psychology, 4(2), 99-105. https://doi.org/10.1080/21683603.2016.1130582

De Munck, V. (2009). Research Design and Methods for Studying Cultures. Plymouth, UK: AltaMira Press.

Dutton, D. G., \& Aron, A. P. (1974). Some evidence for heightened sexual attraction under conditions of high anxiety. Journal of Personality and Social Psychology, 30(4), 510-517. https://doi.org/10.1037/h0037031

Colver, M. C., \& El-Alayli, A. (2015). Getting aesthetic chills from music: The connection between openness to experience and frisson. Psychology of Music, 44(3), 413-427. https://doi.org/10.1177/0305735615572358

Fredborg, B., Clark, J., \& Smith, S. D. (2017). An Examination of Personality Traits Associated with Autonomous Sensory Meridian Response (ASMR). Frontiers in Psychology, 8, 247. https://doi.org/10.3389/fpsyg.2017.00247

Gabrielsson, A., \& Lindström Wik, S. (2003). Strong experiences related to music: A descriptive system. Musicae Scientiae, 7, 157-217. https://doi.org/10.1177/102986490300700201

Gabrielsson, A., \& Lindström, S. (1993). On strong experiences of music. Musikpsychologie: Jahrbuch der Deutschen Gesellschaft für Musikpsychologie, 10, 118-139.

Goldstein, A. (1980). Thrills in response to music and other stimuli. Physiological Psychology, 8, 126-129. https://doi.org/10.3758/BF03326460 
Grewe, O., Nagel, F., Kopiez, R., \& Altenmüller, E. (2007). Listening to music as a re-creative process: Physiological, psychological, and psychoacoustical correlates of chills and strong emotions. Music Perception, 24, 297-314. https://doi.org/10.1525/mp.2007.24.3.297

Guhn, M., Hamm, A., \& Zentner, M. R. (2007). Physiological and musico-acoustic correlates of the chill response. Music Perception, 24, 473-83. https://doi.org/10.1525/mp.2007.24.5.473

Halpern, D.L., Blake, R., \& Hillenbrand, J. (1986). Psychoacoustics of a chilling sound. Perceptual Psychophysics, 38, 77-80. https://doi.org/10.3758/BF03211488

Higham, N. (2014). ASMR: The videos which claim to make their viewers 'tingle'. $B B C$. Posted 11 December 2014. Accessed 30 October 2015. Retrieved from http://www.bbc.com/news/magazine30412358

Huron, D. (2006). Sweet anticipation: Music and the psychology of expectation. Cambridge, MA: MIT Press. https://doi.org/10.7551/mitpress/6575.001.0001

Huron, D. \& Margulis, E.H. (2010). Music, expectation and frisson. In P. Juslin \& J. Sloboda (editors) Handbook of Music and Emotion: Theory, Research, Applications, 2nd edition. Oxford: Oxford University Press, 575-604.

Konečni, V.J. (2015). The Emotional Power of Music: Multidisciplinary Perspectives on Musical Arousal, Expression, and Social Control. Journal of Aesthetics \& Art Criticism, 73, 2.

Konečni, V.J., Wanic, R.A., \& Brown, A. (2007). Emotional and aesthetic antecedents and consequences of music-induced thrills. American Journal of Psychology, 120, 619-643. https://doi.org/10.2307/20445428

Kumar, S., Tansley-Hancock, O., Sedley, W., Winston, J. S., Callaghan, M. F., Allen, M., Cope, T. E., Gander, P. E., Bamiou, D. E., \& Griffiths, T. D. (2017). The Brain Basis for Misophonia. Current Biology, 27(4), 527-533. https://doi.org/10.1016/j.cub.2016.12.048

Lochte, B.C. (2013). Touched through a screen: Putative neural correlates of autonomous sensory meridian response. Unpublished manuscript. Department of Psychological and Brain Sciences, Dartmouth College.

Marks, I. M. (1987). Fears, phobias, and rituals: Panic, anxiety, and their disorders. Oxford University Press on Demand.

Maruskin, L. A., Thrash, T. M., \& Elliot, A. J. (2012). The chills as a psychological construct: Content universe, factor structure, affective composition, elicitors, trait antecedents, and consequences. Journal of Personality and Social Psychology, 103(1), 135-157. https://doi.org/10.1037/a0028117

McErlean, A. B. J., \& Banissy, M. J. (2017). Assessing Individual Variation in Personality and Empathy Traits in Self-Reported Autonomous Sensory Meridian Response. Multisensory Research, 30 (6), 601-613. https://doi.org/10.1163/22134808-00002571

McGraw, A. P. (1999). Expectations and emotions in sports. Masters thesis. Psychology Department, Ohio State University.

McGraw, A. P., \& Warren, C. (2010). Benign violations: Making immoral behavior funny. Psychological Science, 21(8), 1141-1149. https://doi.org/10.1177/0956797610376073

Nusbaum, E. C., \& NC Digital Online Collection of Knowledge and Scholarship (NCDOCKS). (2012). Listening between the notes: Personality, listening context, and aesthetic chills in everyday music listening. Greensboro, N.C.: University of North Carolina at Greensboro. 
Nusbaum, E. C., \& Silvia, P. J. (2011). Shivers and timbres: Personality and the experience of chills from music. Social Psychological and Personality Science, 2(2), 199-204. https://doi.org/10.1177/1948550610386810

Panksepp, J. (1995). The emotional sources of 'chills' induced by music. Music Perception, 13, 171-207. https://doi.org/10.2307/40285693

Panksepp, J., \& Bernatzky, G. (2002). Emotional sounds and the brain: The neuro-affective foundations of musical appreciation. Behavioral Processes, 60, 133-155. https://doi.org/10.1016/S0376-6357(02)00080-3

Ramachandran, V. S. (1998). The neurology and evolution of humor, laughter, and smiling: the false alarm theory. Medical hypotheses, 51(4), 351-354. https://doi.org/10.1016/S0306-9877(98)90061-5

Richard, C. (2014). What is ASMR? ASMR University. Retrieved from https://asmruniversity.com/aboutasmr/what-is-asmr/

Rickard, N. S. (2004). Intense emotional responses to music: A test of the physiological arousal hypothesis. Psychology of Music, 32, 371-388. https://doi.org/10.1177/0305735604046096

Rouw, R., \& Erfanian, M. (2017). A large-scale study of misophonia. Journal of Clinical Psychology, 74 (3), 453-479. https://doi.org/10.1002/jclp.22500

Schröder, A., Vulink, N., \& Denys, D. (2013). Misophonia: diagnostic criteria for a new psychiatric disorder. PLoS One, 8(1), e54706. https://doi.org/10.1371/journal.pone.0054706

Sloboda, J. A. (1991). Music structure and emotional response: Some empirical findings. Psychology of Music, 19, 110-120. https://doi.org/10.1177/0305735691192002

Smith, S. D., Katherine, F. B., \& Kornelsen, J. (2016). An examination of the default mode network in individuals with autonomous sensory meridian response (ASMR). Social Neuroscience, 2016, 1-5.

Taylor, S. (2013). Head orgasms, medition and near-death experiences. The Guardian, Posted 9 October 2013. Accessed 31 October 2014. Retrieved from https://www.theguardian.com/science/brainflapping/2013/oct/09/head-orgasms-meditation-near-death-experiences

Taylor, V. (2014). YouTube videos trigger tingling 'brain orgasms' in ASMR practitioners. New York Daily News, Posted 26 February 2014. Accessed 31 October 2014. Retrieved from http:/www.nydailynews.com/life-style/health/videos-trigger-tingling-brain-orgasms-asmr-believers-article1.1703146

Tufnell, N. (2012). ASMR: Orgasms for your brain. Huffington Post, Posted 26 February 2012. Update 27 April 2012. Accessed 31 October 2014. Retrieved from www.huffingtonpost.co.uk/nicholas-tufnell/asmrorgasms-for-your-brain_b_1297552.html 


\section{APPENDIX 1}

The subject first experienced ASMR as a child, during grade school, and discovered these online videos 3 years ago. The subject frequently watches ASMR videos, typically on a daily basis before bed or during a "lull period" during the day. The subject suggests that it is vital to use headphones to experience ASMR from videos, ideally over-ear headphones to experience the full effects of the audio roaming. She also explained that the sound must be equalized in a certain way to "create a treble-y sound" and eliminate bass. The subject suggests that role-play videos are particularly effective, and expressed a preference for creative content. The subject suggests that good ASMRtists must be non-threatening, more motherly, and generally females are better. She also suggests that she likes nonverbal stimuli, such as the sound of tapping on glass.

The subject describes the sensation as a pleasurable shiver that originates at the shoulder blades and quickly runs up the back of the neck. The subject also experiences frisson, and explains that ASMR is a less emotional experience than frisson. The subject also explains that while watching a video, she may experience ASMR every 30 seconds, whereas frisson may only occur one time.

\section{APPENDIX 2}

Data for Study 1 and a list of video samples are available at: http://hdl.handle.net/1811/86953 